\title{
Separation of Climate Signals
}

\author{
I. K. Fodor and C. Kamath
}

November 13, 2002

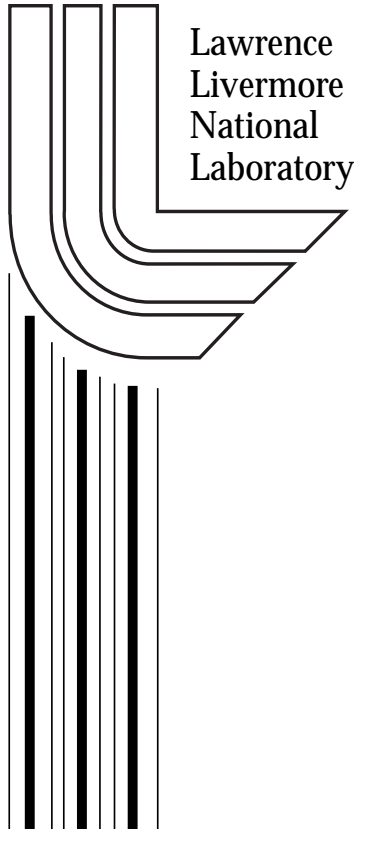




\section{DISCLAIMER}

This document was prepared as an account of work sponsored by an agency of the United States Government. Neither the United States Government nor the University of California nor any of their employees, makes any warranty, express or implied, or assumes any legal liability or responsibility for the accuracy, completeness, or usefulness of any information, apparatus, product, or process disclosed, or represents that its use would not infringe privately owned rights. Reference herein to any specific commercial product, process, or service by trade name, trademark, manufacturer, or otherwise, does not necessarily constitute or imply its endorsement, recommendation, or favoring by the United States Government or the University of California. The views and opinions of authors expressed herein do not necessarily state or reflect those of the United States Government or the University of California, and shall not be used for advertising or product endorsement purposes.

This work was performed under the auspices of the U. S. Department of Energy by the University of California, Lawrence Livermore National Laboratory under Contract No. W-7405-Eng-48.

This report has been reproduced directly from the best available copy.

Available electronically at http://www.doc.gov/bridge

Available for a processing fee to U.S. Department of Energy

And its contractors in paper from

U.S. Department of Energy

Office of Scientific and Technical Information

P.O. Box 62

Oak Ridge, TN 37831-0062

Telephone: (865) 576-8401

Facsimile: (865) 576-5728

E-mail: reports@adonis.osti.gov

Available for the sale to the public from

U.S. Department of Commerce

National Technical Information Service

5285 Port Royal Road

Springfield, VA 22161

Telephone: (800) 553-6847

Facsimile: (703) 605-6900

E-mail: orders@ntis.fedworld.gov

Online ordering: http://www.ntis.gov/ordering.htm

OR

Lawrence Livermore National Laboratory

Technical Information Department's Digital Library

http://www.llnl.gov/tid/Library.html 


\title{
Separation of climate signals
}

\author{
Imola K. Fodor and Chandrika Kamath \\ SciDAC Scientific Data Management Center \\ Data Mining and Access Pattern Discovery Project
}

November 13, 2002

\section{Introduction}

Understanding changes in global climate is a challenging scientific problem. Simulated and observed data include signals from many sources, and untangling their respective effects is difficult. In order to make meaningful comparisons between different models, and to understand human effects on global climate, we need to isolate the effects of different sources.

Recent eruptions of the El Chichón and Mt. Pinatubo volcanoes coincided with large El Niño and Southern Oscillation (ENSO) events, which complicates the separation of their contributions on global temperatures. Current approaches for separating volcano and ENSO signals in global mean data involve parametric models and iterative techniques [3]. We investigate alternative methods based on principal component analysis (PCA) [2] and independent component analysis (ICA) [1]. Our goal is to determine if such techniques can automatically identify the signals corresponding to the different sources, without relying on parametric models. Fig. 1 summarizes our approach.

\section{Results with synthetic data}

ICA has been applied successfully in various source separation problems, such as removing artifacts from EEG/MEG data [3]. Fig. 2 illustrates the method with simple artificial data. In this case, ICA correctly estimates the shapes of two underlying sources $S_{1}$ and $S_{2}$ from the two mixed signals $X_{1}$ and $X_{2}$. As illustrated in Fig. 3, with proper post-processing, the amplitudes of the two sources can also be estimated accurately. Under the assumption of linear mixtures of independent signals, ICA performs well.

\section{Results with climate data}

We obtained monthly mean temperature re-analysis data from the National Centers for Environmental Prediction (http://www.ncep.noaa.gov/). The data is on 


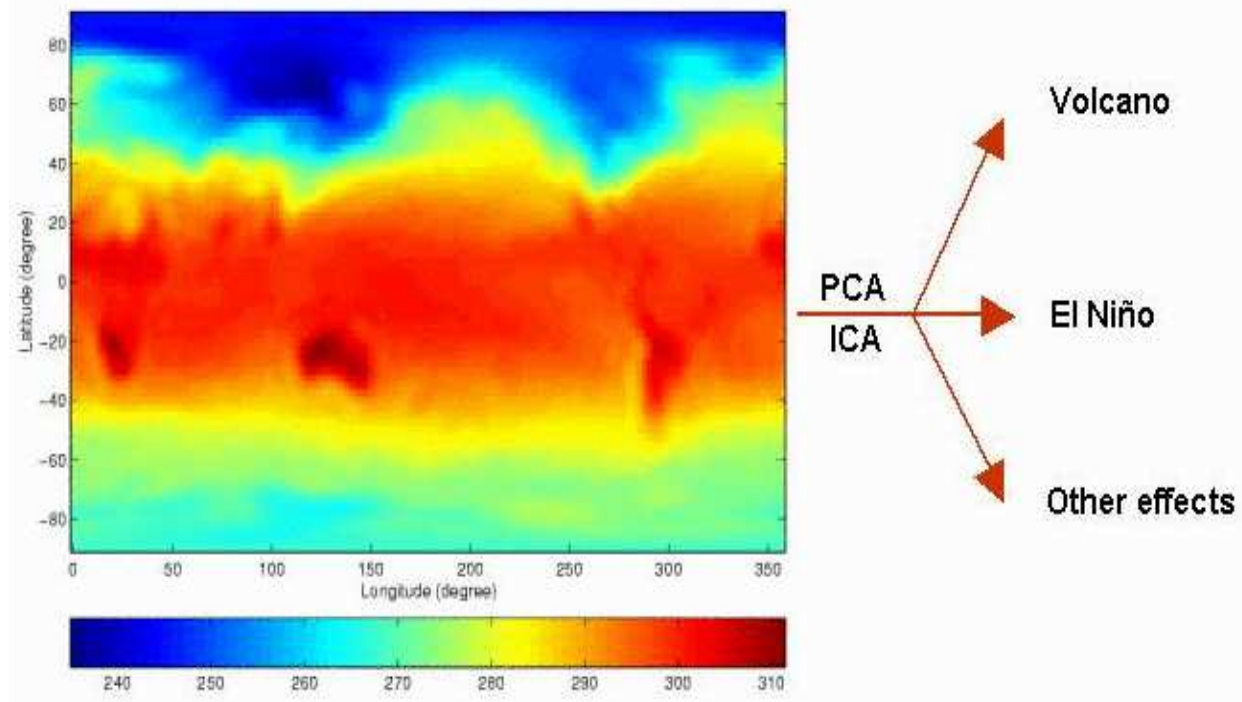

Figure 1: January 1979 raw temperatures (Kelvin) on the 144x73 latitude by longitude grid at $1000 \mathrm{hPa}$ pressure level.

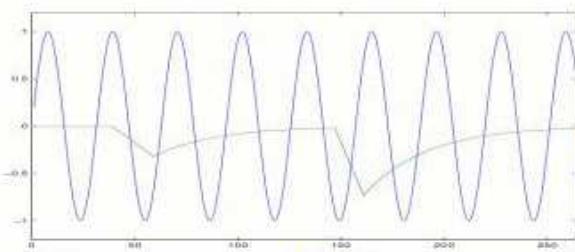

(i) Two IC sources: sine $S_{1}$ and volcano $S_{2}$

$$
\left(\begin{array}{l}
X_{1} \\
X_{2}
\end{array}\right)=\underbrace{\left(\begin{array}{ll}
1.0 & 0.4 \\
0.5 & 0.6
\end{array}\right)}_{\text {Mixing matrix: } A}\left(\begin{array}{l}
S_{1} \\
S_{2}
\end{array}\right)
$$

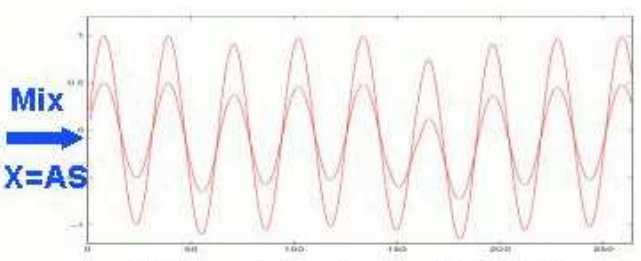

(ii) Two mixed signals: $X_{1}$ and $X_{2}$

ICA

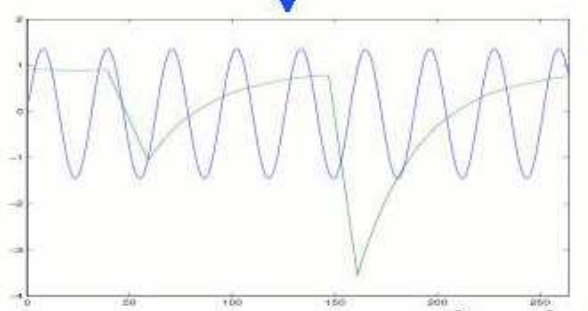

(iii) Sources estimated from (ii): $\hat{S_{1}}$ and $\hat{S_{2}}$

Figure 2: ICA applied to synthetic data. 

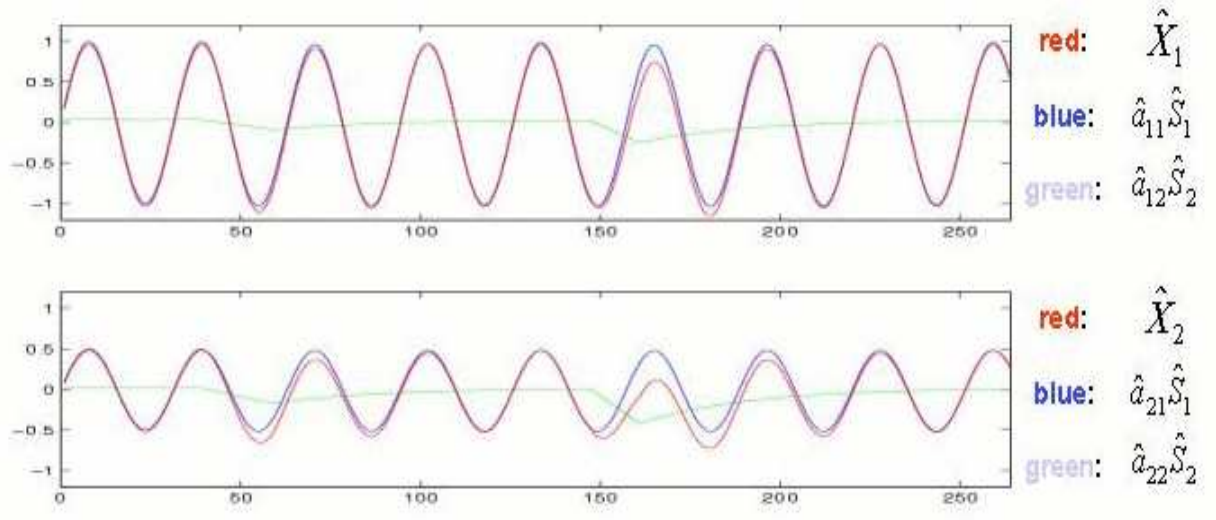

$$
\left(\begin{array}{l}
\hat{X}_{1} \\
\hat{X}_{2}
\end{array}\right)=\hat{A}\left(\begin{array}{l}
\hat{S}_{1} \\
\hat{S}_{2}
\end{array}\right)=\left(\begin{array}{ll}
\hat{a}_{11} & \hat{a}_{12} \\
\hat{a}_{21} & \hat{a}_{22}
\end{array}\right)\left(\begin{array}{l}
\hat{S}_{1} \\
\hat{S}_{2}
\end{array}\right)
$$

Figure 3: The mixed synthetic signals in terms of the estimated independent components.

a 144 x 73 longitude-by-latitude grid, on 17 vertical pressure levels $(1,0000 \mathrm{hPa}$ close to the surface to $10 \mathrm{hPa}$ at the highest elevation), spanning 264 months (22 years, from 1979 to 2000). Since we expected ENSO and volcano signals to have strong latitudinal dependence, we performed our analyses on zonally averaged data. At a given month and level, we first calculated the 73 zonal means (over the 144 longitudes) at the 73 latitudes. Next, following standard practices in the atmospheric sciences [2], we removed the seasonal variation and centered the data as follows. For each month, we replaced the values at each of the $73 \times 17$ latitude-by-level grid points by subtracting their corresponding monthly means over the entire 22-year period. We therefore perform PCA and ICA on a $256 \times 1241$ time-by-space dimension anomaly dataset Z, weighted properly to account for the unequal spatial grid sizes.

Fig. 4 displays the first six basis functions obtained with PCA. The x-axis has 17 pressure levels, the y-axis has 73 latitude values.

Using PCA, we found that the first $\mathrm{k}=22$ PCs explain more than $90 \%$ of the variation. In order to reduce the dimension of the ICA problem, we applied ICA to the $\mathrm{k}=22 \mathrm{PC}$ basis functions. Since the PCs are simply linear combinations of the original data, we can easily obtain the IC coefficients corresponding to the anomaly data by linear transformations of the IC coefficients obtained for the PCs. Fig. 5 displays the resulting IC basis functions. Unlike the PC functions in Fig. 4, the IC functions in Fig. 5 are localized spatially. They do provide an independent basis representation for the data, but they are not interpretable in 


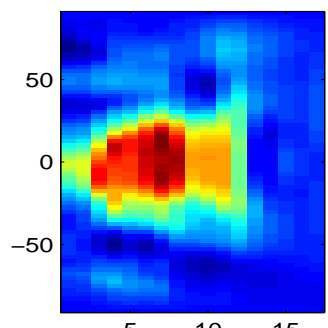

$\begin{array}{lll}5 & 10 & 15\end{array}$
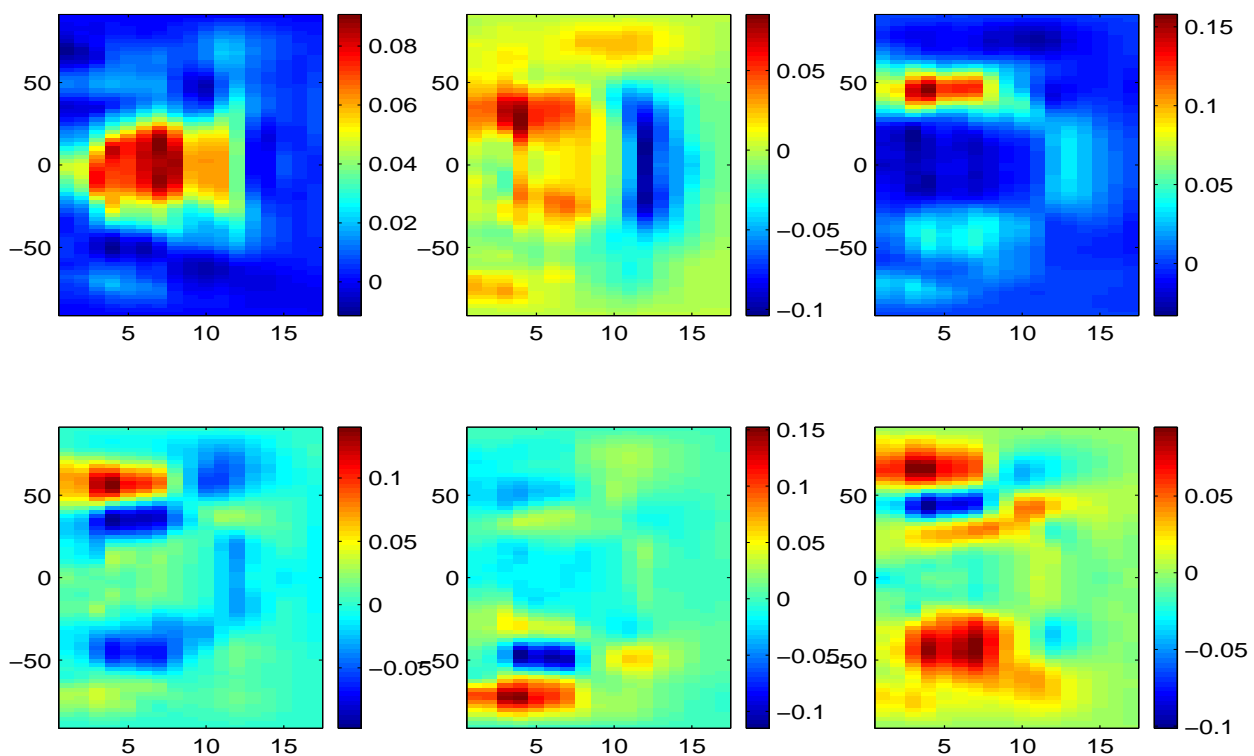

Figure 4: First 6 basis functions, obtained by applying PCA to the zonal anomaly data.

terms of atmospheric processes. Scientific interpretability is a requirement in our case, so next we explored more appropriate ICA models.

Fig. 6 displays the results of applying ICA to the anomaly data projected onto the first $\mathrm{k}=22 \mathrm{PC}$ basis functions. In contrast to the previous ICA method in Fig. 5, the results of this version of ICA appear to be scientifically interpretable.

The next task is to determine which representation is better suited to separate the signals corresponding to the various sources. To answer that problem, we project the data onto the interpretable bases, and thus obtain the corresponding time series coefficients. Fig. 7 shows the projection of the anomalies onto the first $6 \mathrm{PC}$ basis functions in Fig. 4 . The main task is to identify which atmospheric processes the different time series represent.

\section{Summary}

We are currently investigating efficient methods to automatically separate signals in climate data. In addition to the widely used PCA in the climate community, we are also experimenting with the more novel ICA. Our initial results combining ICA with PCA are promising. 

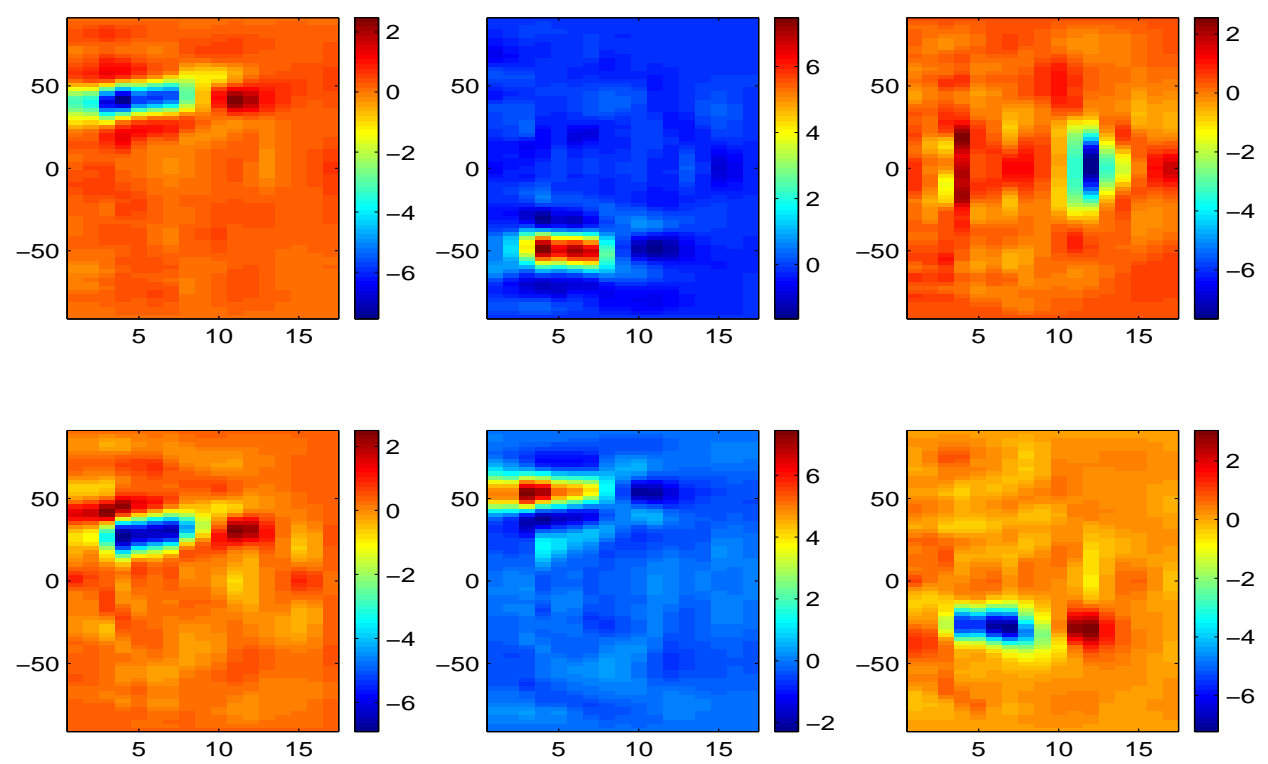

Figure 5: First 6 basis functions, obtained by applying ICA to the first $\mathrm{k}=22$ $\mathrm{PC}$ basis functions.
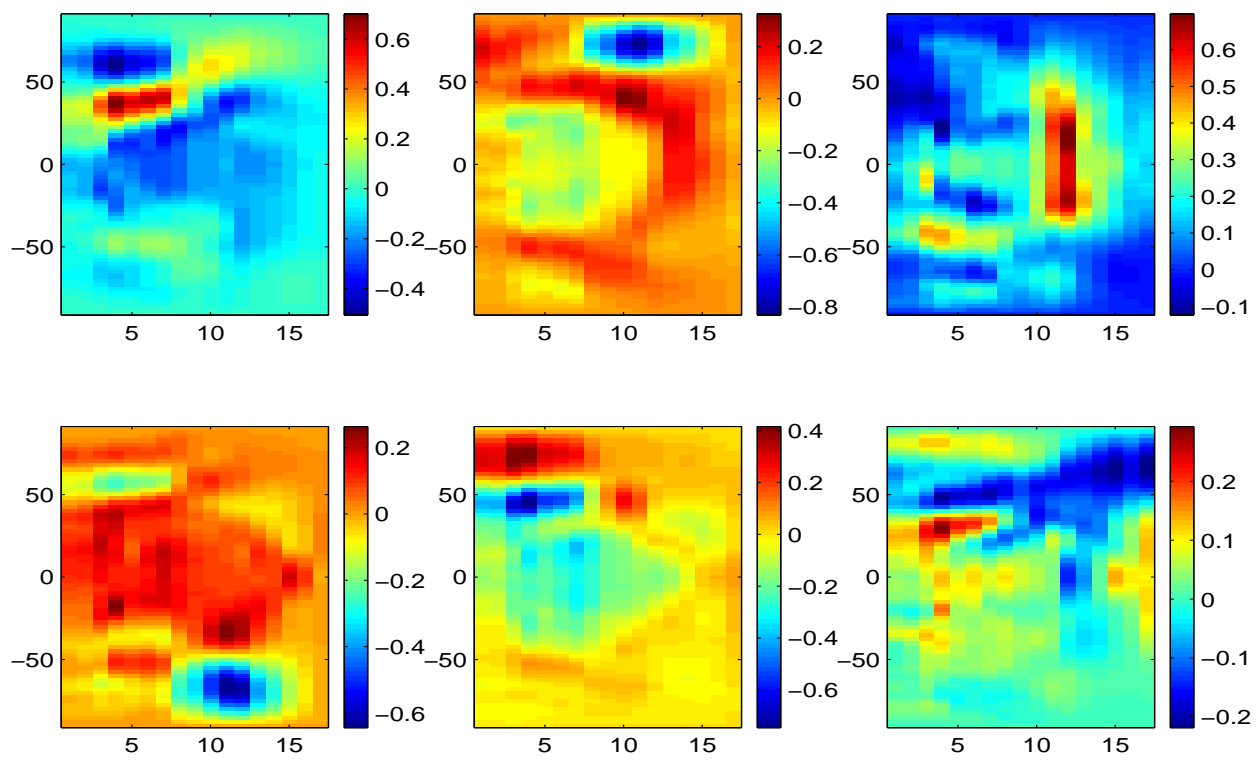

Figure 6: First 6 basis functions, obtained by applying ICA to the anomaly data projected onto the first $\mathrm{k}=22 \mathrm{PC}$ basis functions (i.e. ICA applied to the PC time series coefficients). 


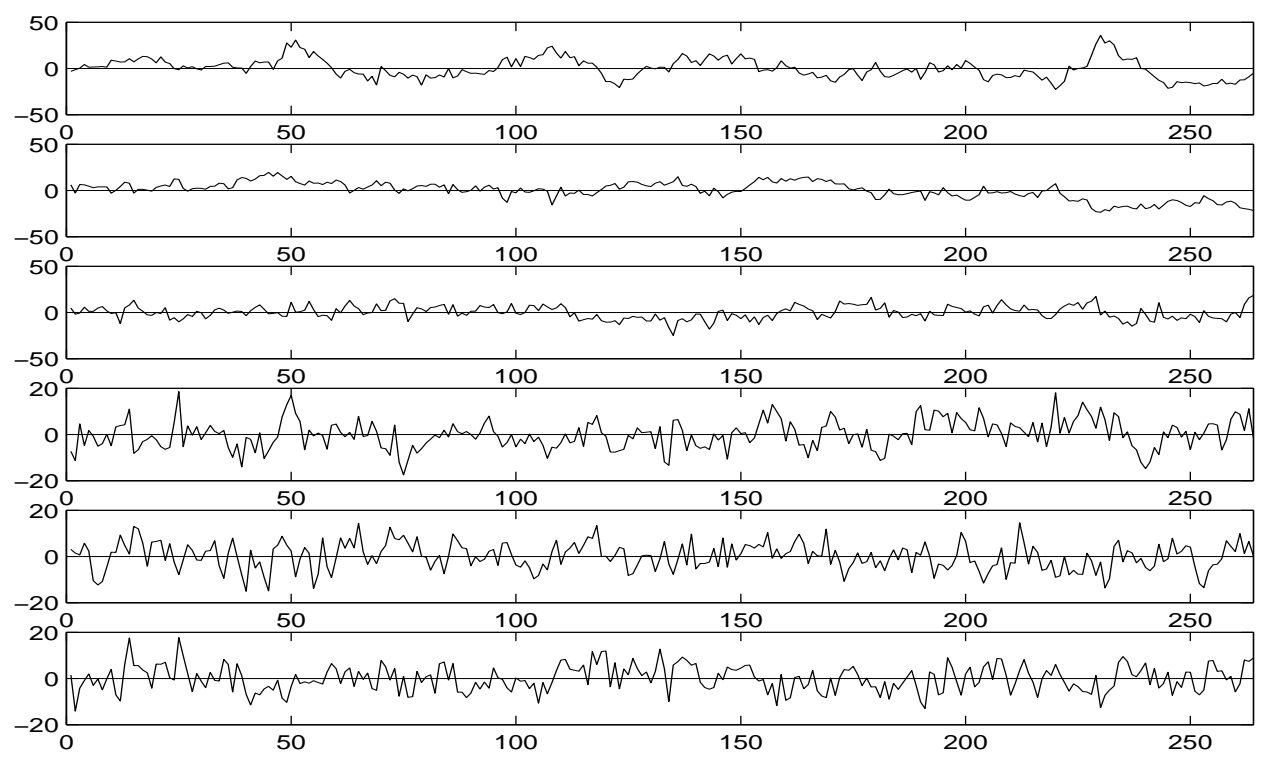

Figure 7: First 6 PC time series coefficients.

\section{Acknowledgments}

We thank Dr. Benjamin D. Santer from the Program for Climate Model Diagnostics and Intercomparison at Lawrence Livermore National Laboratory for introducing us to the problem, for providing the climate data, and for his numerous insights and suggestions.

UCRL-ID-150775. This work was performed under the auspices of the U.S. Department of Energy by University of California Lawrence Livermore National Laboratory under Contract No. W-7405-Eng-48.

\section{Contact info}

For more technical information, contact Dr. Chandrika Kamath at the Center for Applied Scientific Computing, Lawrence Livermore National Laboratory, P.O. Box 808, L-560 Livermore CA 94551, (925) 423-3768, kamath2@llnl.gov, http://www.llnl.gov/casc/sapphire/.

\section{References}

[1] A. Hyvärinen, J. Karhunen, and E. Oja. Independent Component Analysis. Series on Adaptive and Learning Systems for Signal Processing, Communications, and Control. Wiley, 2001. 
[2] R.W. Preisendorfer. Principal Component Analysis in Meteorology and Oceanography. Number 17 in Developments in Atmospheric Science. Elsevier Science, Amsterdam, 1988.

[3] B.D. Santer et al. Accounting for the effects of volcanoes and ENSO in comparisons of modeled and observed temperature trends. Journal of Geophysical Research, 106(D22):28,033-28,059, November 272001. 